\title{
Experiment of hydraulic structure's effect on pollutant transport and dispersion
}

\author{
Huaixiang Liu, Yongjun Lu \\ State Key Laboratory of Hydrology-Water Resources and Hydraulic engineering, \\ Nanjing Hydraulic Research Institute \\ Nanjing, China \\ E-mail address: liuhx@nhri.cn
}

\begin{abstract}
Hydraulic structures have caused many environmental problems in recent years. Structures such as spurdikes are effective in river regulation but also a threat to river ecology. Therefore, in this paper artificial wetland is considered in spur-dike engineering practice for river restoration. In order to study the influence of this ecological project on the discharge of polluted sediment particles, a laboratory experiment was carried out. The flow field and concentration process around the project area was measured under different conditions of discharge, vegetation and sediment concentration input. Results showed that, the reduction of peak concentration was obvious due to velocity variation. The increase of vegetation occupation ratio would lead to the transition of concentration process diagram from 'single-peak' to 'multi-peak' type. And it's very helpful for the enhancement of water quality and the pollutant decomposition. The pollution reduction amounts and the best parameters of this ecological approach were also calculated.
\end{abstract}

Index Terms—Ecology, pollution, sediment, hydrodynamics.

\section{INTRODUCTION}

In hydraulic engineering projects, many environmental and ecological problems have appeared in recent years. Generally they threaten the river ecology through the way of changing water-sediment dynamic structure and river boundary conditions. For example, construction of hydraulic structures may increase the turbidity nearby and so that directly influence the photosynthesis of aquatic vegetation. The erosion and siltation of river bed induced by engineering may also destroy the habitat of creatures. In the 1970s and 1980s, the NanningGuangzhou navigation channel project in the Pearl river built more than 330 hydraulic structures such as spur-dikes. The destruction of aquatic creatures' habitat was enormous. Therefore, how to avoid the ecological threat of hydraulic engineering and to study the relative envrionmet-friendly technology, is a key to the sustainable economic development. Hohmann [1] suggested that, the river regulation should control the stress of human activities and keep the species diversity in order to restore the natural conditions of rivers. Thus the composiation of traditional hydraulic structures and ecological restoration technology is prevailing in both researching and engineering practice. For instance, Lu [2] and Wang [3] studied the application of ecological methods such as artificial fish nest in regulation projects. Among the ecological methods, the artificial wet land is the most common and effective one. It is very helpful in forming aquatic organism communities. The velocity in the dam-field zone of spur-dikes (the bank zone behind dikes) is often slow so that it is very suitable for reconstruction of aquatic vegetation. Then artificial wet land and ecological bank zone will be formed. A study showed that, the wet-land vegetation in lakes could cut $25 \%-62 \%$ of sediment and other pollutants carried by input flow, purifying the water quality. Similarly, the ecological spur-dikes with artificial wet-lands may also affect the land-source polluted flows. The suspended sediment particles, which absorbed pollutants such as heavy metals [4][5], would be especially intercepted in the vegetation. Therefore, a laboratory experiment was designed to quantitatively analyze the pollutant interception effect of this kind of ecological spur-dikes. Then the improvement of projects and relative parameters can be further studied.

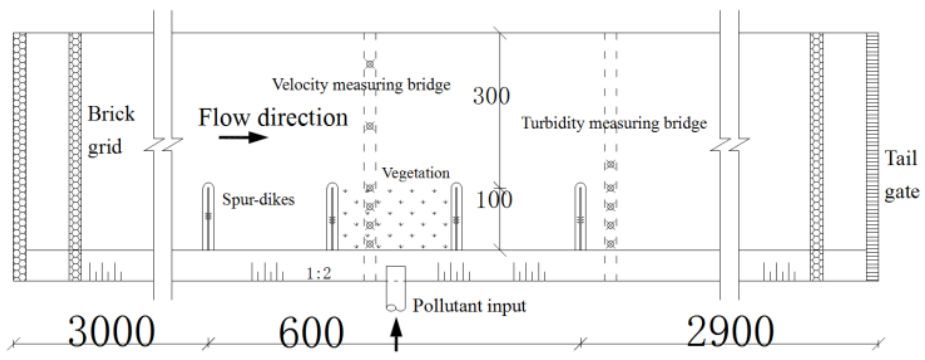

Fig. 1. The layout of laboratory hydrodynamic experiment (Units:cm).

\section{EXPERIMENT DETAILS}

As shown in Fig.1, the size of experiment flume is: $65 \mathrm{~m}$ (length) $\times 4 \mathrm{~m}$ (width) $\times 0.5 \mathrm{~m}$ (height)。Near the both two ends of the flume, there were brick grids for flow stabilizing. A fence-type gate is set in the downstream end to control the water depth. Water flows in the flume can be recycled after passing through the gate. The water from upstream was supplied by the pumps (the largest discharge is $150 \mathrm{~L} / \mathrm{s}$ ).

The experiment section is put in the middle of the flume, 4 spur-dike models with the interval of $2 \mathrm{~m}$ were placed here in order to simulate the real spur-dike group. The distance of experiment section from upstream and downstream were both very far (30m around), so that the influence of entrance and tail gate can be ignored. The dam-field zone between the middle 2 spur-dikes is the wetland simulation zone where polluted water 
is diverted into. In the downstream of spur-dikes, a measuring bridge for turbidimeters placement is set in order to monitor the variation of sediment concentration in this cross-section. At the same time another bridge for velocity measurement is set to obtain the flow field. In this experiment, the turbidity processes in the downstream were recorded under different discharge, wetland area and input polluted sediment concentration. Therefore the interception effect of ecological spur-dikes can be tested in different conditions.

Electromagnetic flow velocimeters which can detect 2D instantaneous velocity and fluctuation were applied for the measurement of velocity and flow field. Sediment concentration in water were measured by laser turbidimeters with the accuracy of $0.001 \mathrm{~g} / \mathrm{L}$. The wooden solid spur-dike models were $100 \mathrm{~cm}$ in length and $6 \mathrm{~cm}$ in height, with the side slope of $1: 1.25$ and head slope of $1: 1.3$. According to several trial run we selected fly-ash for the simulation of polluted sediment particles. The vegetation in artificial wetland were simulated by plastic grasses which distributed in the interval of $5 \mathrm{~cm}$ around.

The prototype of this experiment is the spur-dike regulation section between Guiping and Wuzhou in the Pearl river. According to the local hydrodynamic conditions, it was decided to use undistorted model and the horizontal and vertical scales were about $\lambda_{\mathrm{L}}=\lambda_{\mathrm{H}}=100$, the velocity scale is $\lambda_{\mathrm{u}}=\lambda_{\mathrm{H}}{ }^{1 / 2}=10$.

Two typical input discharge value, the regulation stage discharge and flood discharge, were selected. Then the corresponding discharge in model were calculted by scales. Thus in this experiment there are two conditions: nonsubmerged (regulation stage discharge) and submerged (flood discharge).

'Polluted water' of 6 different pollutant concentrations, $1 \mathrm{~g} / \mathrm{L}, 2 \mathrm{~g} / \mathrm{L}, 4 \mathrm{~g} / \mathrm{L}, 6 \mathrm{~g} / \mathrm{L}, 8 \mathrm{~g} / \mathrm{L}$ and $10 \mathrm{~g} / \mathrm{L}$ respectively, were poured into the artificial wetland, in order to test the response of vegetation interception. For the convenience of comparison, the total volume of every experiment run was the same 50L. In the aspect of artificial wetland, 4 schemes of different vegetation proportions were determined. They were named novegetation, $1 / 3$ vegetation (from bank to $1 / 3$ spur-dike length), $2 / 3$ vegetation (from bank to $2 / 3$ spur-dike length) and full vegetation.

Considering the combination of discharge, input polluted sediment concentration and vegetation proportion, there were $2 \times 6 \times 4=48$ experiment runs.

Experiment step: First prepare the vegetation and polluted water of different concentration; Adjust the flow to steady flow of required discharge and water depth by the control of pump and tail gate; Velocity measurement by the 3points methods $(0.2 \mathrm{~h} 、 0.6 \mathrm{~h} 、 0.8 \mathrm{~h})$, a cross-section for each time, complete all cross-sections by moving the measuring bridge; Discharge the polluted water into the artificial wetland, record the downstream sediment point-concentration; Repeat the experiment run after changing working conditions.

\section{EFFECT ON POLLUTANT}

\section{A. Non-submerged condition}

In Fig.2, some downstream concentration process curves were ploted under the non-submerged condition. And Fig.3 is the similar curves under the submerged condition.

1) The concentration downstream was much smaller than the upstream input concentration due to water dilution. When the input concentration was $1 \mathrm{~g} / \mathrm{L}$, the peak value on the downstream cross section was only about $0.1 \mathrm{~g} / \mathrm{L}$. And the two values would change proportionally: the corresponding peak value of $10 \mathrm{~g} / \mathrm{L}$ (input concentration) was a little smaller than $0.9 \mathrm{~g} / \mathrm{L}$, almost 10 times of $0.1 \mathrm{~g} / \mathrm{L}$. When the vegetation area became larger, the downstream peak value declined to a certain extent. The peak value under full vegetation condition was just $2 / 3$ of the corresponding value under no vegetation condition. That is to say, the vegetation showed the effect of peak clipping.

2) According to the shape of concentration process curve, every point-value start to rise nearly at the same time, which is the time when polluted water reach the measuring cross section. Under the no vegetation condition, the concentration process curve was a distinct single-peak type (Fig.2). It implied that, without any interception the pollutant entered the main stream continuously until the downstream concentration reaching peak value, then the value start to decline since the remained pollutant became less and less after input stop. However, after adding more vegetation a multi-peaks feature appears in the concentration process curve. This means that the pollutant was intercepted and stored in the vegetation zone, so that the continous supply of pollutant into the main stream was disturbed and multi-peaks were formed. In real rivers, this kind of pollutant interception is very important. On the one hand, this effect directly enhanced the water quality and controlled the pollant dissipation. On the other hand, the stored pollutant may be purified by the creatures living in wetland, including microbial decomposition of partial organic compounds and benthos filtration on polluted particles. Thus in that way the ecological function of this spur-dike system could be utilized.

\section{B. Submerged condition}

1) The concentration downstream were also much lower than the input ones. And there was a proportional variation feature as well. But the peak clipping effect of vegetation was not that obvious as the non-submerged case.

2) No matter which vegetation scheme, the concentration of

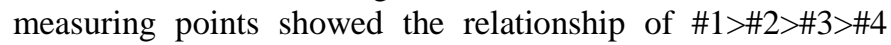
(Fig.3). This result suggested that the polluted current flowed near the bank. Vegetation showed no effect on this phenomenon.

3) As for the curve shape, in all vegeation schemes \#1 value was the earliest one to rise compared with other measuring points. That is, a part of the pollutant input from bank was almost instantly carried to the downstream bank by the strong flow. Furthermore, compared with the nonsubmerged case, the transition from single-peak to multi-peaks 
along with the vegetation area increase was not that impressive (Fig.3).

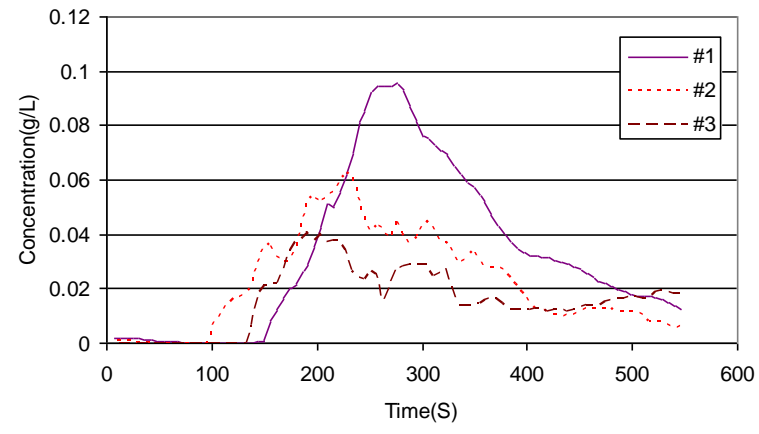

(a) $1 \mathrm{~g} / \mathrm{L}$

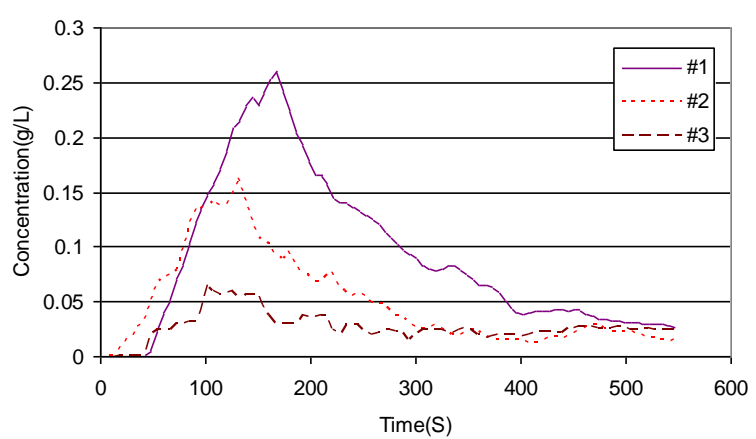

(b) $2 \mathrm{~g} / \mathrm{L}$

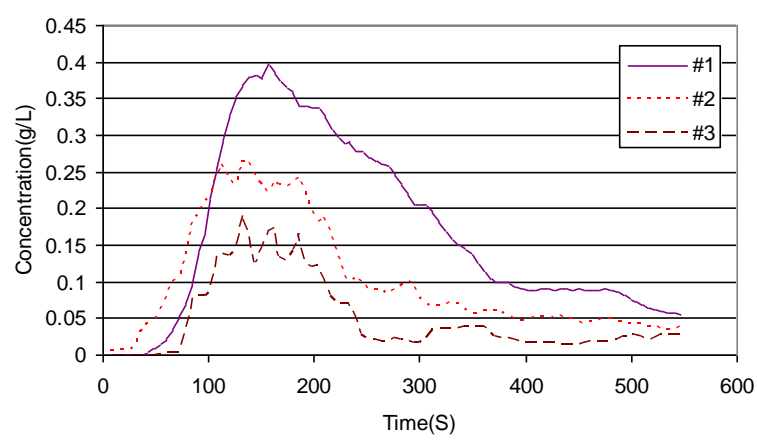

(c) $4 \mathrm{~g} / \mathrm{L}$

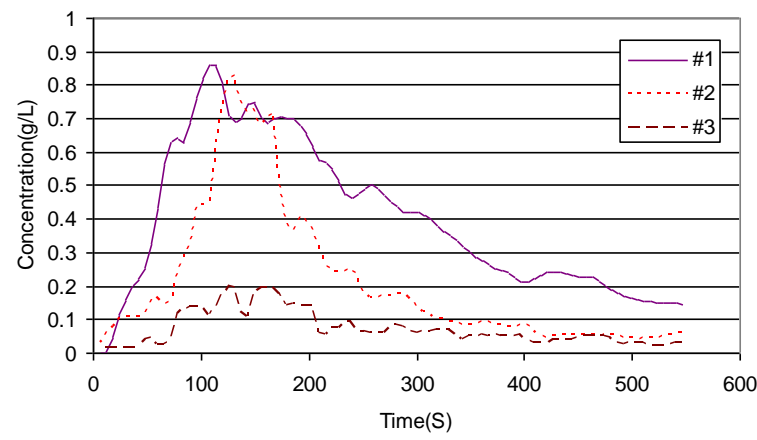

(d) $10 \mathrm{~g} / \mathrm{L}$
Fig. 2. Concentration processes (Non-submerged, no vegetation).

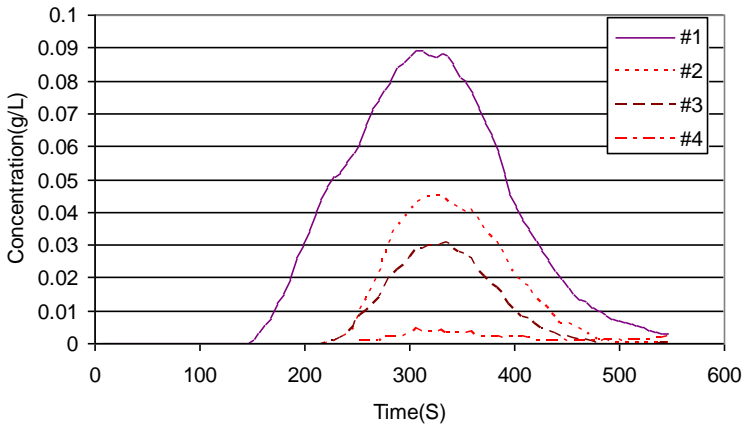

(a) $1 \mathrm{~g} / \mathrm{L}$

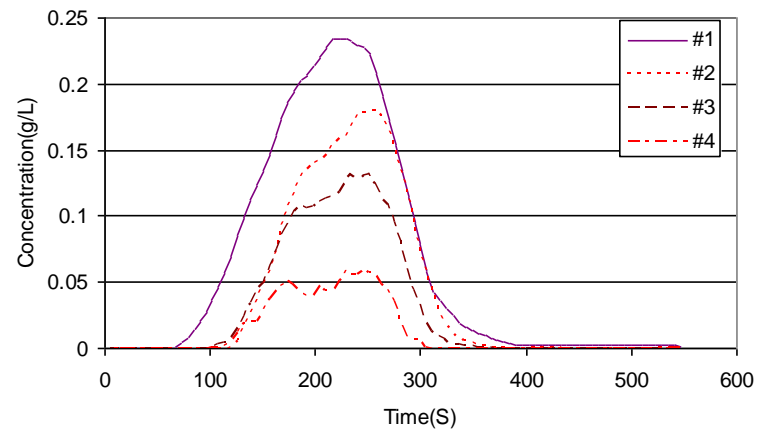

(b) $2 \mathrm{~g} / \mathrm{L}$

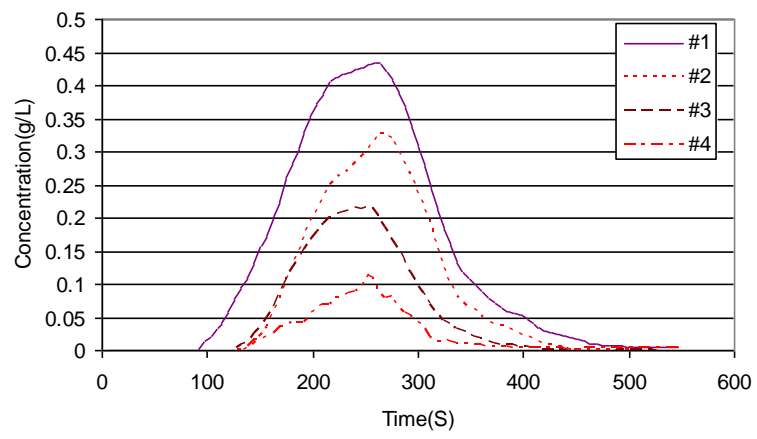

(c) $4 \mathrm{~g} / \mathrm{L}$

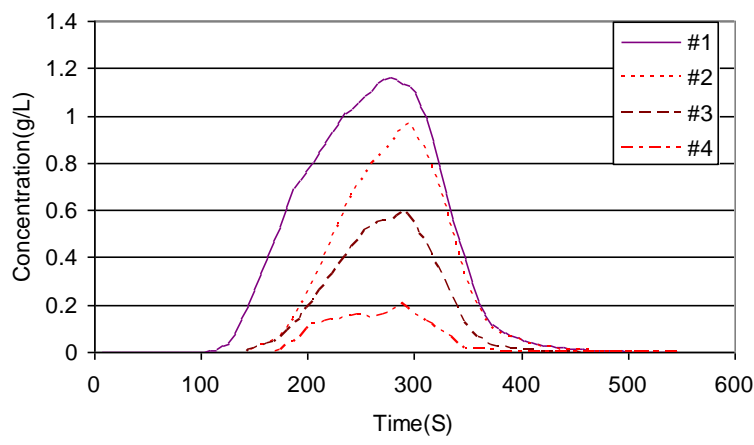

(d) $10 \mathrm{~g} / \mathrm{L}$

Fig. 3. Concentration processes (Submerged, no vegetation). 


\section{Interception calculation}

The results of cumulative pollutants calculation(the area under the concentration curves) indicated that, when nonsubmerged the artificial wetland may impair the cumulative pollutants greatly, reducing $30 \%$ or even more. Thus the vegetation can effectively intercept and store the polluted sediment, decreasing the pollutant entering downstream. The interception effect was obvious even with just $1 / 3$ vegetation, but the importance of vegetation area can be revealed along with the increase of input concentration. For example, when inputing $10 \mathrm{~g} / \mathrm{L}$ polluted water, $1 / 3$ vegeation could only reduce $10.5 \%$ of the cumulative pollutants, while the effect of $2 / 3$ vegetation and full vegetation were $21.3 \%$ and $39.6 \%$ respectively. This means that, large pollutant input may exceed the 'store capacity' of vegetation so that the vegetation area should be expanded to store more pollutant.

\section{CONCLUSIONS}

In this paper, a laboratory hydrodynamic flume experiment was carried out to investigate the function of artificial wetland in ecological spur-dike system. The results indicated that:

1) The increase of vegetation may decrease the overall velocity or just increase the near-bank back flow, especially under non-submerged condition. Thus the polluted sediment could be intercepted more easily. When submerged, the influence of vegetation was restricted only in the near-bed area due to large velocity and depth.

2) A transition from single-peak to multi-peaks along with the vegetation area increase was shown in the downstream concentration process curves. The peak clipping function of artificial wetland can reduce the downstream concentration, implying that the polluted sediment were intercepted and stored in the ecological spur-dike zone. Furthermore, the water quanlity can be enhanced and the detained pollutant can be biological treated in the real wetland.

3) The interception effect of artificial wetland on input pollutant was estimated. when non-submerged the reduced proportion could reach $30 \%$ or even more. Thus the vegetation can effectively intercept the polluted sediment. This effect was obvious even with just $1 / 3$ vegetation near-bank, but large pollutant input may exceed the 'store capacity' of vegetation so that the vegetation area should be expanded to store more pollutant. When submerged, the intercept proportion was relatively small and greatly affected by the vegetation area.

4) It can be concluded that, the pollutant-interception effect of ecological spur-dikes with artificial wetlands is good. The ecological function is obvious under the normal discharge condition (non-submerged). If the wetland area is restricted by the requirement of flood discharge or navigation, then the nearbank part of wetland can still play the similar function. As for frequently flooded or highly bank-source polluted river sections, the wetland area should be expanded as large as possible. During the floods, some pollutant can directly over flow the spur-dikes. Thus some improverment such as ecological design of the dike body (surface vegetation and so on) can also be considered.

\section{ACKNOWLEDGMENT}

This work was financially supported by the National Basic Research 973 Program of China (Grant No. 2012CB417002) and the National Natural Science Foundation of China (Grant No. 51009096).

\section{REFERENCES}

[1] J. Hohmann and W. Konold, "Flussb aum as snahmen an der wutach und ihre bew ertung au s oekologischer sicht," Deutsche Wasserw irtschaft, 1992, 82(9):434.440.

[2] Y. Lu, S. Q. Li and Y. J. Lu, "Ecological effects and stability of an artificial reef spur-dike," Proceedings of the 7th IAHR Symposium on River, Coastal and Estuarine morphodynamics. Beijing, China, 2011: 512-522.

[3] P. F. Wang, C. Q. Yang and C. Wang, "Study on effect of ecological groin on velocity of flow and sediment deposition," Poceedings of the 23rd national Conference on hydrodynamics, Xi'an, 2011:697-701.

[4] R. T. James, J. Martin, T. Wool and P. Wang, "A sediment resuspension and water quality model of lake okeechobee," Journal of the American Water Resources Association, 1997, 33: 661-680.

[5] G. Pan, "Adsorption kinetics in natural waters: a generalised ion-exchange model, in adsorption and its application in industry and environmental protection," Studies in Surface Science and Catalysis, 1999, 120: 745-761. 